\title{
Effect of EMS on induced morphological mutants and chromosomal variation in Cowpea (Vigna unguiculata (L.) Walp)
}

\author{
S. Gnanamurthy, D. Dhanavel* \\ Division of Cytogenetics and Mutation Breeding, Department of Botany, \\ Annamalai University, Annamalai Nagar - 608002, Tamil Nadu, India \\ *E-mail address: ddhana2005@yahoo.co.in
}

\begin{abstract}
Effect of EMS (ethyl methane sulphonate) on induced morphological mutants and chromosomal variation in cowpea was studied using five different doses of mutagen along with a control in randomized blocked design with three replications. The morphological mutants there are two types of viable and chlorophyll mutants. Viable mutant contains tall, dwarf, early maturity, late maturity, leaf mutants pod mutant and flower mutants. The frequency of chlorophyll mutant contains albino, xantha and viridis. This concentration can damage or modify important components of plant cells and have been reported to affect the morphology, anatomy, biochemistry and physiology of plants differentially depending on the concentration level. These effects include changes in the cellular structure and metabolism of the plants e.g., dilation of thylakoid membranes, alteration in photosynthesis, modulation of the antioxidative system and accumulation of phenolic compounds. The morphological and chromosomal variation was found to be mutagen sensitive in somatic cells of cowpea. It was found to increase with increasing the concentration of EMS in Cowpea plants. The chemical mutagen like ethyl methane sulphonate induces high frequency of chromosomal changes like anaphasic bridge; anaphasic laggard, anaphasic bridge and clumbing of chromosome were including control plants also observed.
\end{abstract}

Keywords: EMS; Morphological; Mutation; chromosomal aberration; Cowpea

\section{INTRODUCTION}

Cowpea is one of the most important pulse crops in tropical Africa. The seeds are a major source of dietary protein in most developing countries. Induced mutation breeding has been recognized as a valuable supplement to the conventional breeding in crop improvement programmes and has been least applied in grain legumes. Cowpea (Vigna unguiculata (L.) Walp) forms major food crop of millions of people in most developing countries. It belongs to the kingdom plantae, division Magnoliophyta, class Magnoliopsida, order Fabales, family Fabaceae, Sub-family Faboideae, genus Vigna and species unguiculata [30].

Induced mutations are highly effective in enhancing natural genetic resources and have been used in developing improved cultivars in cereals, fruits and other crops [20]. These 
mutations provide beneficial variation for practical plant breeding purpose. During the fast seven decades, more than 2252 mutant varieties have been officially released in the world [21]. A great majority of mutant varieties $(64 \%)$ were developed by the use of gamma rays [2]. In India still today there are 7 mutant varieties of cowpea released by both physical and chemical mutagens [23]. Hence, mutation- breeding programme has proved to be a successful tool in bringing amelioration in self- pollinated crops.

Chemical mutagen generally produce induced mutations, which lead to base pair substitution especially GC to AT resulting in amino acid changes, which changes the function of proteins, but do not abolish their functions. These chemo mutagens also induce a broad variation of morphological and yield structure change in comparison to normal plants. Alkylating agents such as ethyl methane sulphonate (EMS) induce chemical modification of nucleotides, which result in mispairing and base changes. Strong biased alkylation of guanine (G) residue results, forming $\mathrm{O}^{6}$-ethyl guanine, which can pair with thymine (T) but not with cytosine (C). Through subsequent DNA repair, the original G/C pair can then be replaced with A/T. Ninety-nine percent of mutations from alkylation of guanine induced by EMS are reported as $\mathrm{G} / \mathrm{C}$-to-A/T transitions [12].

The chromosome number of this crop is $2 \mathrm{n}=22$ [4,25,27]. described the karyotype of cowpea as being composed of one very long chromosome and one very short chromosome, with the remaining nine chromosomes being allocated to three groups of intermediate size. On the other hand, [25] described 11 chromosome pairs falling into three sized groups: five long, five medium, and one short.

\section{MATERIALS AND METHODS}

The dry and dormant seeds of the cowpea variety CO-7 were obtained from Milled Breeding Station, Tamilnadu Agricultural University, and Coimbatore. The present study on induced mutagenesis in Cowpea was carried out in the Botanical Garden, Department of Botany, Faculty of Science, and Annamalai University during 2011-2012. The chemical was obtained from HI- MEDIA Laboratories, Mumbai, having a half life period of 30 hours with a molecular weight of 124.16 and density of 1.20. Seed treated from Two Sets containing 200 well filled healthy seeds were selected for treatment. To determine the $\mathrm{LD}_{50}$ values, seeds were pre soaked in distilled water for 6 hours followed by EMS at 0 (control), 5, 10, 15, 20, $25,30,35,40,45$ and $50 \mathrm{mM}$ concentrations.

The seeds after soaking in EMS were thoroughly washed in running tap water for 8 to 10 times and transferred to Petri dishes containing two layers of moist filter paper for germination. Ten Petri dishes of 10 seeds per treatment were planted and Percentage germination and seedling variations for each treatment were subsequently determined. The treated seeds were then subjected to germination test. Based on the reduction of germination to 50 per cent, $\mathrm{LD}_{50}$ value was determined.

Three concentrations of EMS around $\mathrm{LD}_{50}$ were fixed for further studies. In field observation from morphological characters like tall, dwarf, early maturity, late maturity, leaf mutants pod mutant and flower mutants. The frequency of chlorophyll mutant contains albino, xantha and viridis. All the characters observed in $\mathrm{M}_{2}$ generation. 


\section{1. Cytological method}

The root tips collected from control and treated seedling were fixed in 1:3 acetic ethanols. The root tip squashes were made by using Iron alum Haematoxylin squash technique [22]. The root tips were hydrolyzed in $0.1 \mathrm{~N} \mathrm{HCl}$ for 5 to 10 minutes at $60{ }^{\circ} \mathrm{C}$ and then they were thoroughly washed in distilled water and transferred to $4 \%$ iron alum for 3 minutes.

The root tips were then washed in distilled water and transferred to ripened dilute Haematocylin stain and kept for 3 hours.

The root tips were thoroughly washed in distilled water and then they were treated in 45 $\%$ acetic acid being a de-staining agent, the time of study in Haematoxylin had to be adjusted to the time required for softening in acetic acid. One or two root tips were placed on a clean slide and squashed by using a cover slip and the slide was sealed and mounted in DPX solution and then examined. The normal and abnormal mitotic stages were photographed.

\section{RESULT AND DISCUSSION}

Cytological analysis with respect to their mitotic behaviour is considered to be one of the most dependable indices to estimate the potency of mutagen. Cytological studies provide information regarding the response of cowpea genotypes to a particular mutagen and provide greater chances for the selection of desired characters.

Root tip mitotic studies revealed a wide range of chromosomal aberration such as anaphasic bridge with laggard, anaphasic multiple bridges and laggards, anaphasic bridge, clumping of chromosome.

The chromosome studies were made in treated plants $\mathrm{M}_{2}$ generation such as EMS treatments. Chromosome laggards were observed for $25 \mathrm{mM}$ concentrations. In the present study, the aberrations caused by mutagens are due to partial or complete failure of spindle mechanism. Maximum chromosome aberrations were observed in EMS (30 mM) when compared to control. Root tip squash was carried out in the different concentration of 20, 25 and $30 \mathrm{mM}$ of EMS treated seedlings. In the present study, some of the cytological behaviour likes normal metaphase, anaphasic laggards, anaphasic bridge, metaphase chromosomes were also observed (Plate-1, Fig: a, b, c, d and e.).

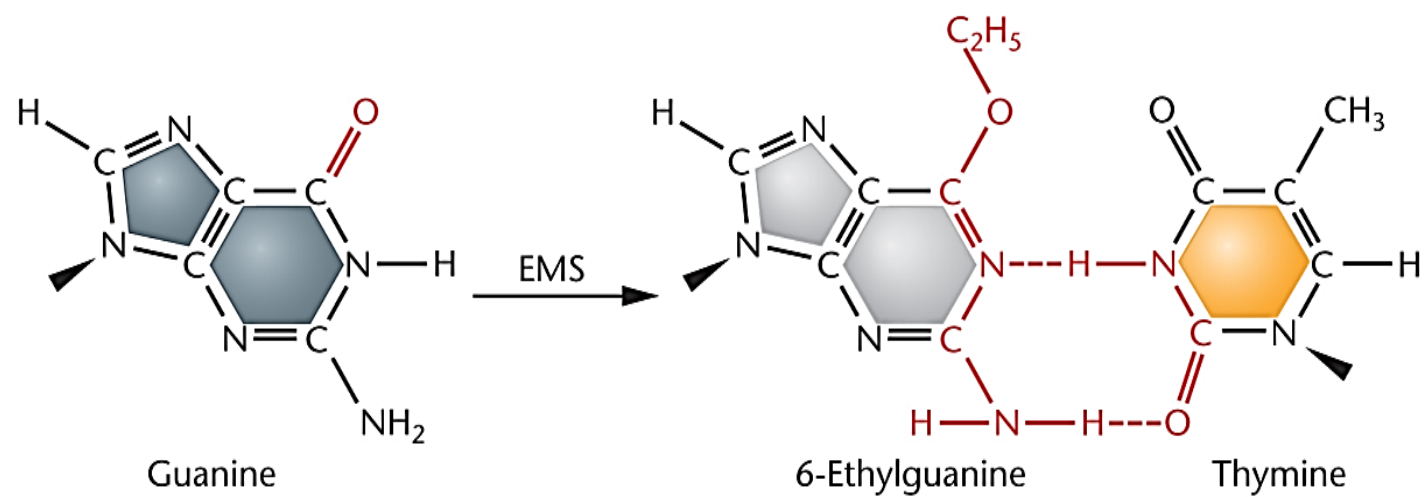

The mutagenic action of EMS results from its reaction with DNA by alkylating the phosphate groups $[3,15]$ suggested that the triesters formed due to alkylation of the 
phosphate groups by EMS are unstable and tend to lose the alkyl group but it is not known if these alkyl groups are liable to infer with DNA replication. Alkylation of a phosphate can cause breakage of the linkage between deoxyribose and phosphate.

The extract consequences of such an event are however, unknown. EMS shows more specification to guanine and cytosine [9] and specifically N-7 position of guanine is highly susceptible to alkylation by the mutagen [5,6]. Incorporation of alkyl group into a base may result in the formation of a gap in the DNA template $[18,19]$ and subsequent replication defects leading to mutations.

EMS treatment causes alkylation of guanine bases $(\mathrm{G})$ leading to mispairing or mismatch pairing in the DNA of a treated organism. Under these conditions, an alkylated $\mathrm{G}$ pairs with $\mathrm{T}$ (thymine) in place of $\mathrm{C}$ (cytosine), causing a $\mathrm{G} / \mathrm{C}$ to $\mathrm{A} / \mathrm{T}$ transition in the backbone of the DNA. EMS treatments can cause allelic mutations, small deletions and other chromosomal rearrangements. These mutations can be used to activate morphometric and reproductive changes in plants; further selection of mutant plants through a number of generations can be used to eliminate deleterious mutations, resulting in introduction of new traits into a treated population [1].

\section{1. Viable Mutants}

Mutations are phenotypically classified into two groups [10]; macro mutations: These are easily detectable in individual plants, phenotypically visible and morphologically distinct and they are qualitatively inherited genetic changes, and occur in major genes or oligogenes; and micro mutations: These result in a small effect that, in general, can be detected only by help of statistical methods and quantitatively inherited genetic changes, and occur in minor genes or polygenes. All the characters which are of interest to plant breeders can be either altered or amended by mutations. It is also possible to induce new features which do not exist in the available range of variability in a high yielding and well adapted variety.

The plant height was highly increased with higher number of branches and clusters when compared to control. These mutants were observed in almost all the mutagenic treatments especially $20 \mathrm{mM}$ of EMS (Plate-2, Fig: a). the mutants showed plant height was very much reduced with less number of branches and clusters when compared to control. The maximum of three mutants were observed at $30 \mathrm{mM}$ of EMS (Plate-2, Fig: b). the mutants showed 10-15 days earlier maturity than the control plants. The maximum of three mutants were observed at $25 \mathrm{mM}$ of EMS treatment (Plate-2, Fig: c). the mutants exhibited 5-10 days late maturity than the control plants, one or two mutants were observed at $30 \mathrm{mM}$ of EMS (Plate-2, Fig: d). The mutants showed 5 leaflets which were observed at all mutagenic treatments especially $25 \mathrm{mM}$ of EMS (Plate-2, Fig: e). The pod number increasing was higher than the control. The maximum of five pods were observed at $25 \mathrm{mM}$ of EMS (Plate-2, Fig: $\mathrm{f}$ ). Ten pink colored flowering were observed at $25 \mathrm{mM}$ of EMS treatment (Plate-2, Fig: g). the five light pink colored flowering were observed at $20 \mathrm{mM}$ of EMS treatment (Plate-2 Fig: $\mathrm{h}$ ). Frequency of chlorophyll \& viable mutants showed by table-1.

In the present investigation, tall and dwarf mutants were observed in different mutagenic treatments. Among the concentration maximum number of mutants was recorded at $25 \mathrm{mM}$ of 0f EMS treatment. Similar results were observed by [32] in kodomillet, [16] in Capsicum annuum. Leaf mutant isolated may be called progressive in term of $[11,24]$ explained the phylogenetic significance of leaf mutants. Radiation/chemical mutagen induced cellular damage results in the alteration of metabolism which ultimately leads to leaf abnormalities. Leaf abnormalities were attributed to the chromosomal breakage, disturbed auxin synthesis, disruption of mineral metabolism and accumulation of free amino acids [13]. 


\section{PLATE-1}

\section{Chromosome Observations in Cowpea (Vigna unguiculata (L.) Walp)}

A

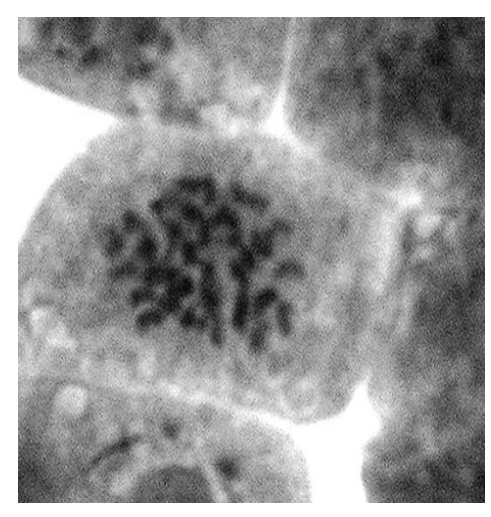

C

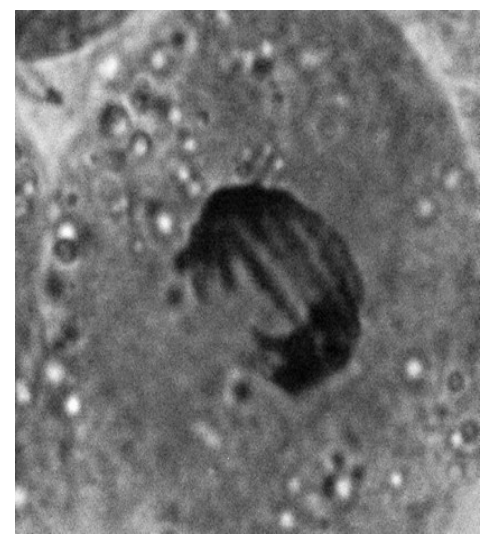

B

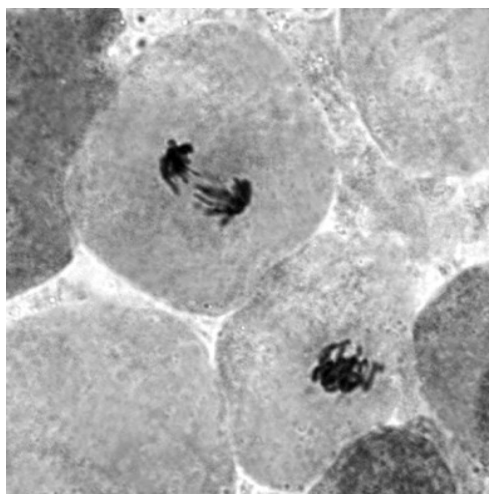

D

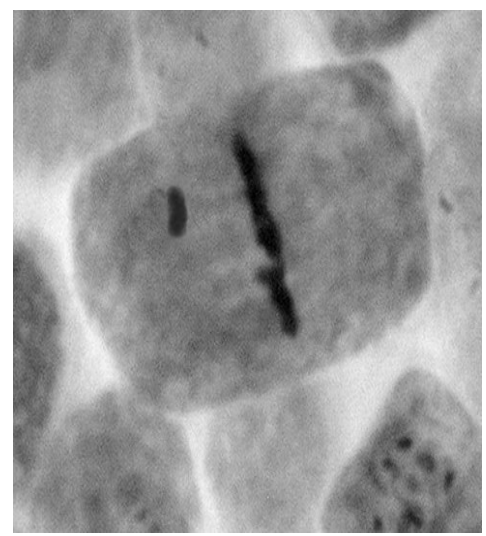

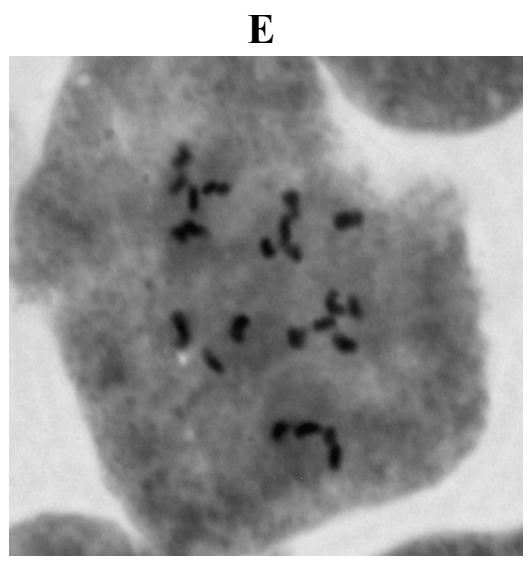

Fig:

a) Metaphase ( $2 n=22$ control)

b) Anaphasic bridge and clumping of chromosomes (20mM EMS) 
c) Anaphasic bridge (25 mM EMS)

d) Anaphasic laggard (25 $\mathrm{mM}$ EMS)

e) Metaphase Chromosome $2 \mathrm{n}=23(30 \mathrm{mM}$ EMS $)$

\section{PLATE-2}

Morphological Mutants observations in cowpea (Vigna unguiculata (L.) Walp) Viable Mutants

A

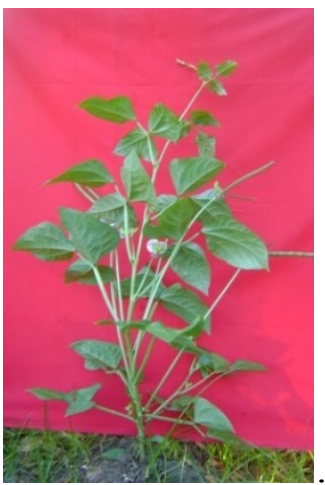

E

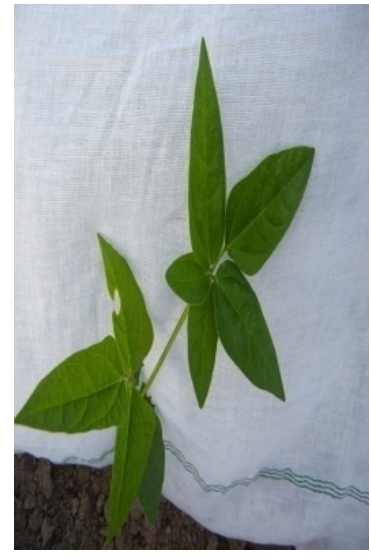

$\mathrm{B}$

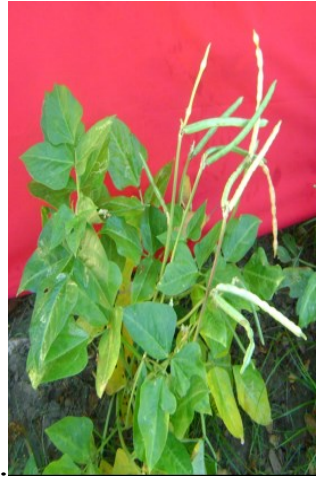

F

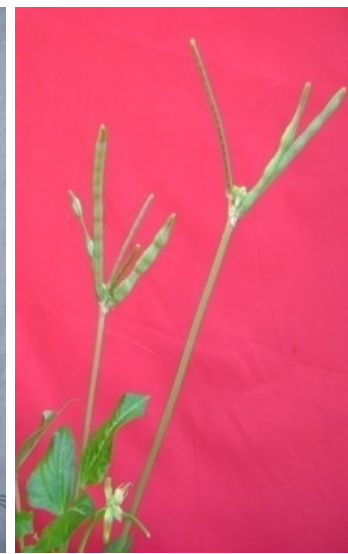

C

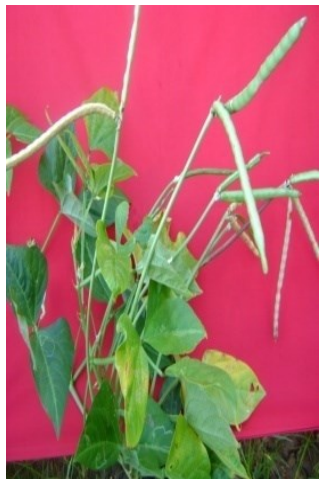

G

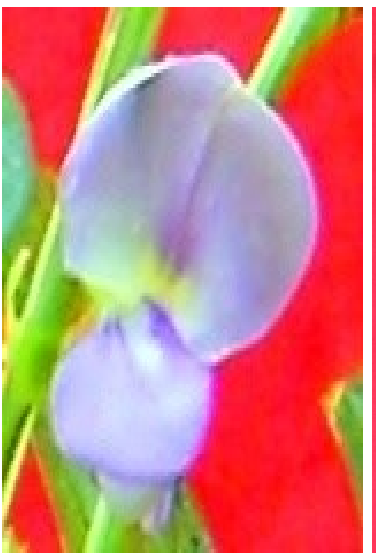

$\mathrm{D}$

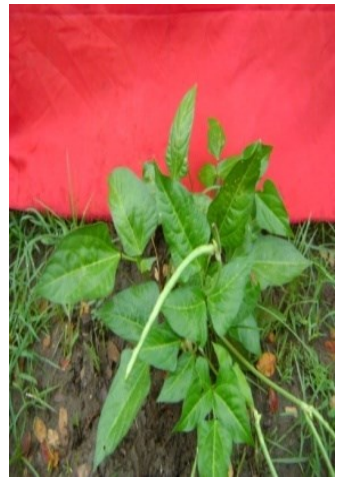

$\mathrm{H}$

Fig:
a) Tall plant (20 $\mathrm{mM}$ EMS)
b) Dwarf plant (30 mM EMS)
c) Early maturity (25 mM EMS)
d) Late Maturity (30 $\mathrm{mM}$ EMS)
e) Leaf Mutant (25 mM EMS)
f) Pod Mutant (25 mM EMS)
g) Pink colour flower (25 mM EMS)
h) Light pink colour flower (20 mM EMS) 


\section{PLATE-3}

Chlorophyll Mutants observations in cowpea (Vigna unguiculata (L.) Walp)

$\mathbf{A}$

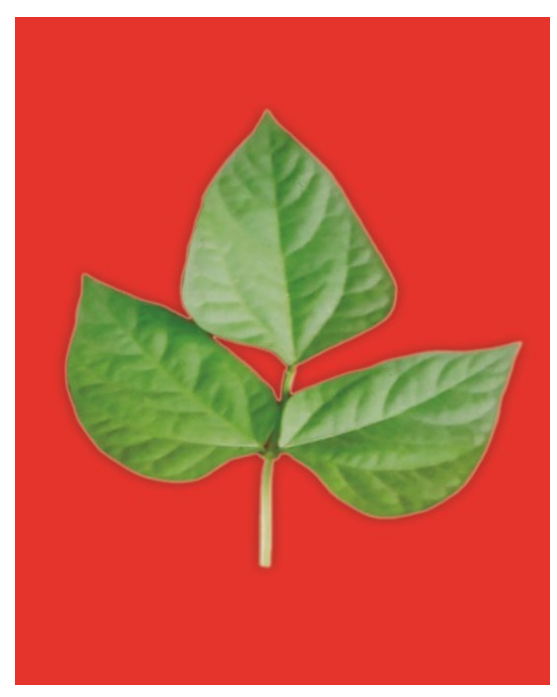

C

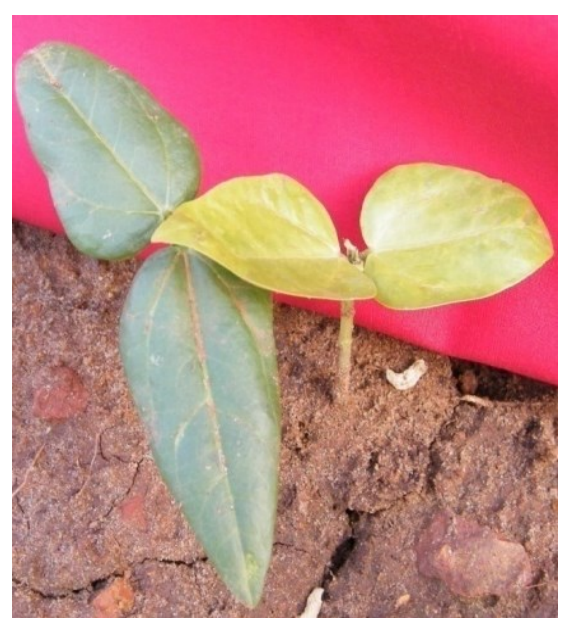

B

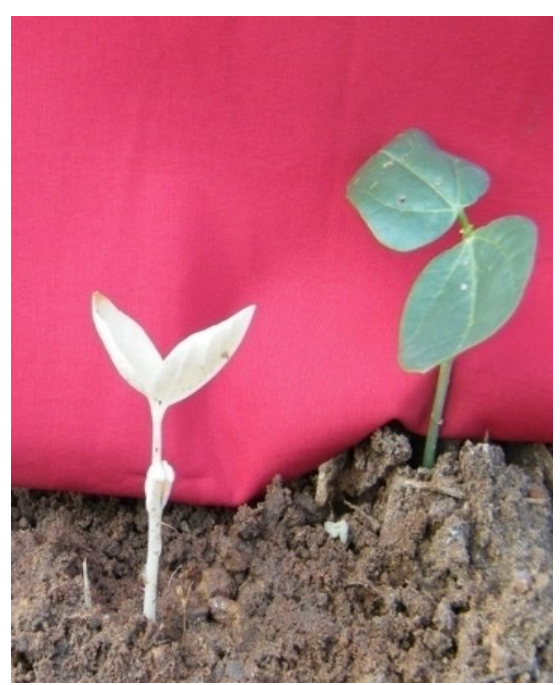

$\mathrm{D}$

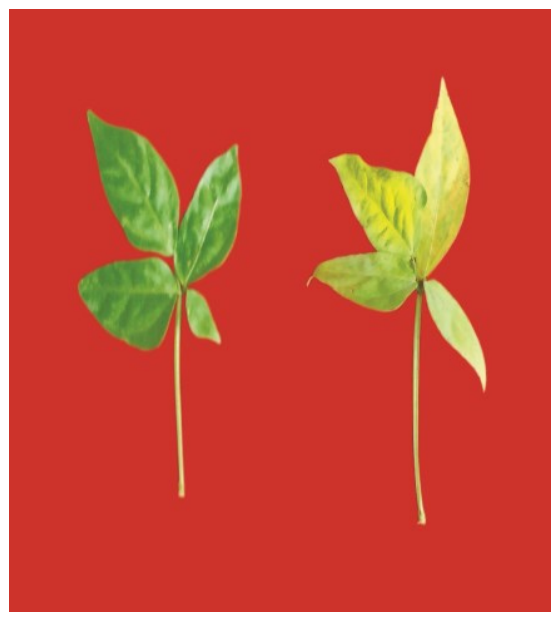

Fig:
a) Control Plant
b) Albino (25 $\mathrm{mM}$ EMS)
c) Xantha (20 mM EMS)
d) Xantha (30 mM Ems) 
Table 1. Frequency of Chlorophyll \& Viable Mutants in $\mathrm{R}_{2}$ Generation.

\begin{tabular}{|c|c|c|c|}
\hline \multirow{2}{*}{$\begin{array}{c}\text { Dose/Concentration of } \\
\text { Mutagens }\end{array}$} & \multicolumn{3}{|c|}{ Ethyl methane sulphonate (EMS) } \\
\hline & $20 \mathrm{mM}$ & $25 \mathrm{mM}$ & $30 \mathrm{mM}$ \\
\hline No of Plants Studied & 545 & 575 & 530 \\
\hline Albino & 1 & 2 & 1 \\
\hline Viridis & 1 & 1 & 1 \\
\hline Xantha & 1 & 2 & 1 \\
\hline Tall & 3 & 2 & 1 \\
\hline Dwarf & 1 & 1 & 2 \\
\hline Early Flowering & 1 & 2 & 1 \\
\hline Tetra Foliate leaf & 1 & 2 & 1 \\
\hline Penta foliate leaf & 1 & 2 & 1 \\
\hline Early Maturity & 1 & 2 & - \\
\hline Late Maturity & - & 1 & 2 \\
\hline Brown Color Seed & 1 & 2 & 1 \\
\hline White Color Seed & 1 & 2 & 1 \\
\hline Bold size Seed & 2 & 3 & 1 \\
\hline Single Seed Pod & - & 1 & 1 \\
\hline Long Pod & 2 & 2 & - \\
\hline Male Sterility & 1 & - & 1 \\
\hline Total & 18 & 27 & 16 \\
\hline Frequency & 3.30 & 4.72 & 3.01 \\
\hline
\end{tabular}

$$
F=\frac{\text { Total Number of Mutants }}{\text { Total Number of plant Studied }}
$$

$(\mathrm{F})=$ Frequency 
The leaf mutant such as penta foliate leaf was observed at $25 \mathrm{mM}$ of EMS. Similar results were reported by [28] in sesame. [29] isolated a few pentafoliate and tetrafoliate mutants from the gamma rays and EMS treated mungbeans. The pod mutant such as single seeded pod and long pod were observed. High number of pod mutant was observed at $25 \mathrm{mM}$ of EMS treatments. Early pod mutant were reported by [31] in lentil and [17] in black gram. Flower mutants such as early flowering, pink color flower and light pink colour flower were also observed in all mutagenic treatments. Similar results were observed by [26] in Artemisia pallens; [8] in sesame; [7] in sesame.

\section{2. Chlorophyll mutants}

The spectrum of chlorophyll mutations viz., albino, xantha and virescence were observed at all mutagenic treatments. However, highest frequency of chlorophyll mutation was recorded. The $\mathrm{M}_{2}$ seedlings were screened from $15^{\text {th }}$ to $20^{\text {th }}$ day to record the various chlorophyll mutants periodically. The classification and identification of the chlorophyll mutants was done based on the nomenclature adopted by [14]. The mutation frequency was estimated on $\mathrm{M}_{2}$ seedling basis. Albino, these mutant leaves were white in colour, due to absence of all pigment. This was leaded to the death of the plants at 10-15 days after germination (Plate-3, Fig: b). Xantha, the leaves turned yellow in colour due to the absence of xanthophylls (Plate-3, Fig: c). Viridis, these mutants showed leaf margin more segregated at compared to control. Young leaves were pale green in during maturity time. One or two mutants were observed at all mutagenic treatments (Plate-3, Fig: d). and control plant (Plate-3, Fig: a).

\section{CONCLUSION}

The improved variety of cowpea CO-7 responded more and more number of viable and economic mutants for higher productivity in $25 \mathrm{mM}$ of EMS than the other mutagenic treatments in all generations. The morphological mutant characters studied can be utilized for identification and characterization of cowpea genotypes. Cytological studies provide information regarding the response of cowpea genotype CO-7 to a particular mutagen and provide greater chances for the selection of desired characters. The present investigation revealed that the isolation of early maturity with high yield and high protein content is possible in $25 \mathrm{mM}$ of EMS.

\section{References}

[1] Acharya, S.N., J.E. Thomas and S.K. Basu, 2007. Improvement in the medicinal and nutritional properties of fenugreek (Trigonella foenum-graecum L.). In: S.N. Acharya, J.E. Thomas (eds) Advances in medicinal plant research, Research Signpost, Trivandrum, Kerala, India.

[2] Ahloowalia, B.S., M. Maluszynski, and K. Nichterlein. 2004. Global impact of mutationderived varieties. Euphytica, 135: 187-204.

[3] Alexander, P. and K.A. Stacey, 1958. Comparison of the changes produced by ionizing radiation and by the alkylating agents: evidence for a similar mechanism at the molecular level. Ann. New York Acad. Sci. 68: 1225. 
[4] Barone, A. and F. Saccardo, 1990. Pachytene morphology of cowpea chromosomes. In cowpea genetic resources. Edited by N.Q. Ng and L.M. Monti. IITA Ibadan, Nigeria. Pp. 137-143.

[5] Bautz, E. and Freese, E. 1960. On the mutagenic effects of alkylating agents. Proc. Natl. Acad. Sci, 46: 1585.

[6] Brockes, P. and P.D. Lawley, 1960. The reaction of mustard gas with nuclei acid in vivo and in vitro. J. Biochem, 77: 478.

[7] Chowdhury, S., A. K. Datta and S. Maity, 2009. Cytogenetical and agronomical aspects of radiation induced marker trait mutants in sesame (Sesamum indicum L.), Indian J. Sci and Tech, 2(5): 58-61.

[8] Diouf, M., S. Boureima, T. Diop and M.Cagirgan, 2010. Gamma rays-induced mutant spectrum and frequency in sesame, Turk. J. Field Crops, 15(1): 99-105.

[9] Freese, E. 1963. Molecular mechanism of mutations. Molecular Genetics. Academic Press, pp. 207.

[10] Gaul, H., 1964. Mutation in plant breeding. Rad. Bot., 4: 155-232.

[11] Gottschalk, W., 1972. Combination of mutated genes as an additional tool in plant breeding. In: induced mutations and plant improvement, IAEA Vienna, pp. 199-215.

[12] Greene E. A., et al., 2003. Spectrum of chemically induced mutations from a large-scale reverse-genetic screen in Arabidopsis. Genetics, 164(2): 731-740.

[13] Gunkel, J.K. and A.H. Sparrow, 1961. Ionizing radiations: biochemical, physiological and morphological aspects of their effect on plants. In: W. Rubland (ed.). Encyclopedia of plant physiology, Springer, Berlin. 16: 555-611.

[14] Gustafsson, A., 1940. The mutation system of the chlorophyll apparatus. Lond Univ. Arsskr., 36: 1-40.

[15] Heslot, H. 1965. The nature of mutations. Rad. Bot. 5: 3-45.

[16] Jabeen, N., and B. Mirza, 2004. Ethyl methane sulfonate induces morphological mutations in Capsicum annuum. Int. J. Agri. Biol, 6 (2): 340-345.

[17] Juliet Hepziba, S. and M. Subramanian, 2002. Induced macromutants in $\mathrm{M}_{3}$ and $\mathrm{M}_{4}$ generations of blackgram (Vigna mungo (L.) Hepper). Crop Res., 24(1): 63-66.

[18] Kreig, D.R. 1963. EMS induced reversion of bacteriophage $\mathrm{T}_{4}$ rII mutants. Genetics, 48: 561.

[19] Lawley, P.D., 1966. Effects of some chemical mutagen and carcinogens on nuclei acids. Progr. Nucleic acid Res. Mol. Bio, 5: 89.

[20] Lee, Y. I., I.S. Lee and Y.P. Lim, 2002. Variation in sweet potato regenerates from gamma-rays irradiated embryogenic callus. J. Plant Biotech, 4: 163-170.

[21] Maluszynski, K.N., L.N. Zanten and B.S. Ahloowalia, 2000. Officially released mutant varieties. The FAO/IAEA Database. Mut. Breed. Rev, 12: 1-12.

[22] Marimuthu, K.M. and M.K. Subramaniam, 1960. An iron alum haematoxylin squash schedule for the root tips of Dolichos lablab L. Curr. Sci., 29: 482-483. 
[23] Natarajan, A.T., 2005. Chemical mutagenesis: from plants to human. Curr. Sci. 89(2): 312-316.

[24] Nerkar, Y.S., 1973. Induced mutations of polygenic significance in Lathyrus sativus. Indian J. Genet, 33: 324-325.

[25] Pignone, D., S. Cifarelli and P. Perrino, 1990. Chromosome identification in Vigna unguiculata (L.) Walp. In Cowpea genetic resources. Edited by N.Q. Ng and L.M. Monti. IITA Ibadan, Nigeria. pp. 144-150.

[26] Rekha, K. and A. Langer, 2007. Induction and assessment of morpho-biochemical mutants in Artemisia pallens Bess. Genet. Resour. Crop. Evol, 54: 437-443.

[27] Saccardo, F., A. Del Giudice, and I. Galasso, 1992. Cytogenetics of cowpea. In Biotechnology: enhancing research on tropical crops in Africa. Edited by Thottappilly, G., L.M. Monti, D.R. Mohan Raj, and A.W. Moore. Technical Centre for Agricultural and Rural Cooperation, Wageningen, The Netherlands, and the International Institute of Tropical Agriculture, Ibadan, Nigeria, pp 89-98.

[28] Sengupta, S. and A.K. Datta, 2005. Induced narrow leaf mutant of sesame (Sesamum indicum L.). Indian J. Genet., 65(1): 59-60.

[29] Singh, B.B., D.R.Mohan Raj, K.E. Dashiell and L.E.N. Jackai (Eds.), 1997. Advances in cowpea research, co publication of international institute of tropical agriculture (IITA) and Japan international research center for agricultural sciences (JIRCAS), IITA, Ibadan, Nigeria. Sayce publishing, Devon, UK.

[30] Singh, V.P. and R. Sharma. 1993. $\gamma$-rays and EMS induced leaf mutants in mungbean (Vigna radiata (L) Wilczek). Curr. Sci, 65: 636-638.

[31] Vandana., and D.K. Dubey, 1995. Frequency and spectrum of mutations induced by NMU and DES in khesari (Lathyrus sativus L.) var. EC-50 (Macrosperma). Res. J. Pl. Environ., 11: $5-9$.

[32] Yadava, H.S., A.N. Tikle and D.V. Bhagat, 2003. Effect of induced mutation through gamma rays on growth and yield parameters of kodo-millet. J. Soil and Crops, 13(1): $25-28$. 